\title{
The Calculation and Analysis of Distribution Network Loss with Photovoltaic Power Generation Connected
}

\author{
Bi Wang ${ }^{1, \text { a }}$,Yingying Sun ${ }^{2, b}$, Feifan $\mathrm{Lu}^{1, \mathrm{c}}$, Xin $\mathrm{Wu}^{1, \mathrm{~d}}$, \\ Zhongyao Liu $^{2, ~ e}$, Wenjie Dong ${ }^{2, f}$ \\ ${ }^{1}$ Shenzhen Power Supply Co., Ltd.Shenzhen, China; \\ ${ }^{2}$ Dongfang Electrics Co., Ltd.Yantai, China. \\ aytdfsunyy@163.com, bsunyystudy@163.com
}

Keywords: distribution network loss, photovoltaic power generation, average current theoretical, PV power installation location, PV capacity.

Abstract. As a direct power supply to the distribution network user side, the photovoltaic power generation has a positive effect on reducing line loss of distribution network. However the loss reduction of PV power is conditional. The photovoltaic power installation location and the generating capacityboth affect the distribution network loss. In this paper, a method for distribution network loss calculation with the PV power connected is presented. And it simulates and analyses the affecting on network loss from both the PV power installation location and the generating capacity.

\section{Introduction}

Photovoltaic power generation is a direct power supply to the user side, which has a positive effect on reducing the loss of distribution network. However, the loss reduction of PV power is conditional. Photovoltaic power installation location and rated capacity will affect the loss of distribution network [1]. A steady-state model of the photovoltaic grid-connected is presented. The effects of PV power to the loss of distribution network is calculated and analyzed.

\section{Average Current Theoretical of Line Loss Calculation}

The average current theoretical of line loss calculation is a method derived from the RMS current method. In this method, the equivalence relation of RMS current and average current is used to calculate the network power loss. The basic concept of the average current theoretical is: the network power loss caused by average current flowing in the line is equal to the network loss caused by the actual load in the same time. However, the loss calculated by the average current theoretical method is littler than the RMS current method. So a modified coefficient which is larger than 1 is needed.

The introduction of the PV generation will bring new opportunities on the economic operation of distribution network [2]. A method suitable for distribution network line loss analysis with PV power connected is crucial. In this paper, the average current theoretical is used to calculate the line loss of distribution network. The effects of PV power to the loss of distribution network is calculated and analyzed [3]. 
The average current theoretical is derived by mean square root current method, and it bases on equivalent of the mean square root current and the average current to calculate the power loss. The basic concept of average current theoretical is the power loss produced by the average current flowing in the line is equal to the actual electric energy loss in the same time [4].

Loss power consumption calculation formula:

$$
\Delta A=\frac{A_{P}^{2}+A_{Q}^{2}}{U_{a r}^{2}} \cdot k^{2} \cdot R \cdot t \cdot 10^{-3}=3 I_{a r}^{2} \cdot k^{2} \cdot R \cdot t \cdot 10^{-3}
$$

$\Delta \mathrm{A}$ is the loss power consumption;

$A_{p}$ is the daily active electricity comsumption;

$\mathrm{A}_{Q}$ is the daily reactive electricity comsumption;

$\mathrm{U}_{a r}$ is the daily average voltage;

$\mathrm{R}$ is the element total equivalent resistance;

$\mathrm{t}$ is the time(hour);

$I_{a r}$ is the average current.

$\mathrm{k}$ is the modified coefficient.

The modified coefficient $\mathrm{k}$ is:

$$
\mathrm{k}=\frac{I_{\text {eff }}}{I_{\text {ar }}}(2)
$$

$I_{\text {eff }}$ is the RMS current;

$I_{a r}$ is the average current.

The value of $\mathrm{k}$ is associated with the change of load curves. It can be calculated by the load factor fand the minimum load factor $\beta[5]$.

When the load factor $f$ is equal or larger than 0.5 , it has the follow formula.

$$
\mathrm{k}^{2}=\frac{\beta+\frac{1}{3} \cdot(1-\beta)^{2}}{\left(\frac{1+\beta}{2}\right)^{2}}(3)
$$

When the load factor $\mathrm{f}$ is little than 0.5 , it has:

$$
\mathrm{k}^{2}=\frac{f(1+\beta)-\beta}{f^{2}}(4)
$$

As the actual load of electric power system is changing all the time, the power losses in the distribution network also change over time [6]. The distribution network energy loss calculation formula is:

$$
\begin{gathered}
\Delta A=\int_{0}^{T} \Delta P \cdot K^{2} d t \\
=\int_{0}^{T} \frac{A_{P}^{2}+A_{Q}^{2}}{U_{a r}^{2}} \cdot k^{2} \cdot R \cdot 10^{-3} d t=\int_{0}^{T} 3 I_{a r}^{2} \cdot k^{2} \cdot R \cdot t \cdot 10^{-3} d t
\end{gathered}
$$

The excellent feature of average current method is it has high reliability and is ease to programming realization. However, because of the transformers data are often not measured in distribution network, this method is not accurate enough.

\section{Calculation of distribution network loss with distributed PV generation connected}

In the calculation of the distribution network loss with PV power connected, the impact of distributed PV generation on distribution network voltage is generally ignoredand the node voltage of distribution network is assumptive to be equal for every node. If the in ject power of 
PV is $P_{P V}+j \cdot Q_{P V}$, the unit line resistance is $\mathrm{R}+\mathrm{j} \cdot \mathrm{X}$, the distance from the PV to the supply power is $\mathrm{N}$ and the distance from the PV to the load is $\mathrm{M}$.

The loss of distributed network without PV is:

$$
\mathrm{P}=\frac{\left(P_{\text {load }}^{2}+Q_{\text {load }}^{2}\right)}{U} \cdot(R+j X) \cdot M(6)
$$

The loss of distributed network with PV connected is:

$$
\begin{gathered}
\mathrm{P}=\frac{\left(P_{\text {load }}-P_{p v}\right)^{2}+\left(Q_{\text {load }}-Q_{p v}\right)^{2}}{U} \cdot(R+j X) \cdot N \\
+\frac{\left(P_{\text {load }}^{2}+Q_{\text {load }}^{2}\right)}{U} \cdot(R+j X) \cdot(M-N)(7)
\end{gathered}
$$

It shows that the network loss with PV connected is both affected by the photovoltaic power installation location and the generating capacity. When the capacity of PV is smaller than the load power multiplied by two, the PV can reduce the network loss.

However, the distributed PV power plays a supporting role to the network voltage, especially distributed PV power and the voltage outlets and its adjacent node is obvious. The influence of distributed PV power to node voltage should be full considered, and the effects of PV power to the loss of distribution network is calculated and analyzed.

\section{Example analysis}

Using aregional distribution network as a model for simulation and analysis, the total injection line power is 10MVA. The structure of the regional distribution network shows in figure 1 .

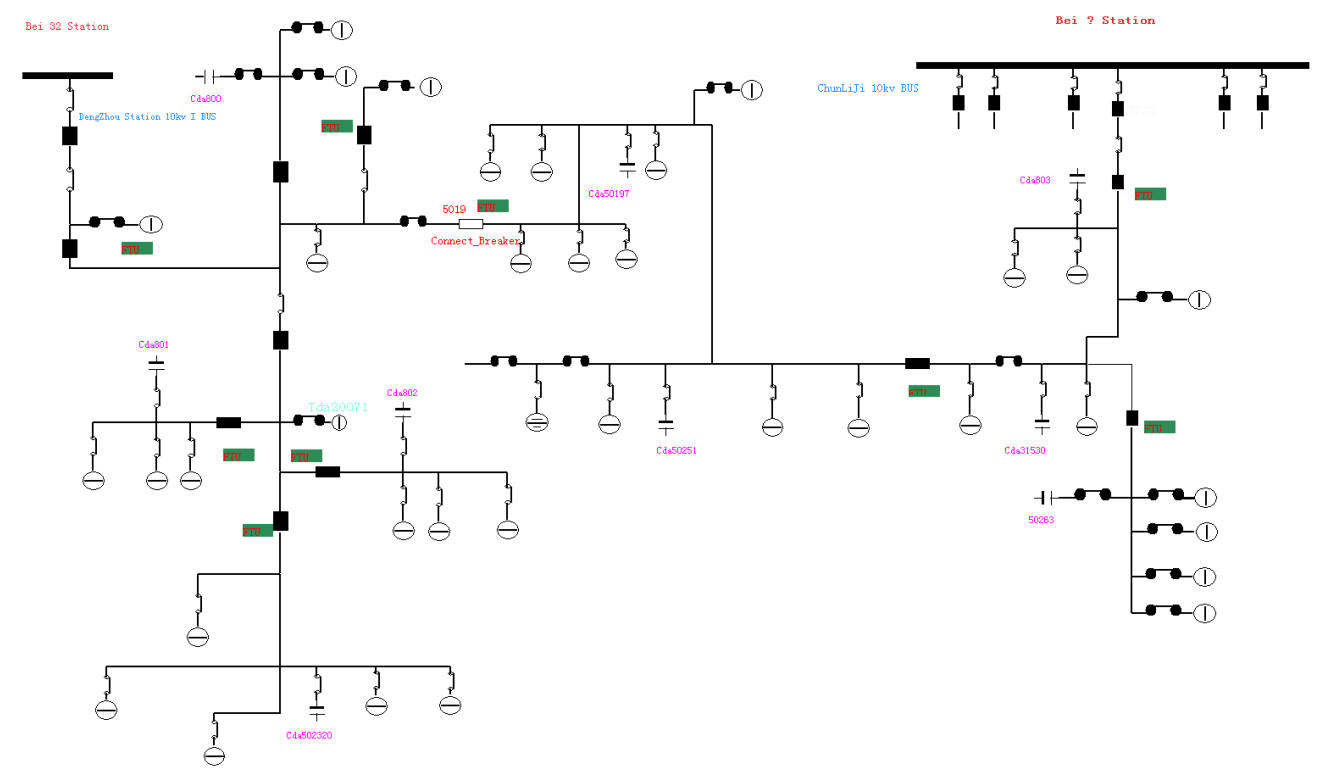

Figure 1 The structure of the regional distribution network

\section{Analysis on the effects of the PV capacity to distribution network loss}

In the regional distribution network, the PV generation is connected to a node of network head, middle or end, and the percentages of PV capacity on the total load capacity respectively 
are $5 \%, 10 \%, 15 \%, 20 \%, 25 \%, 30 \%$. The table 1 , table 2 and table 3 show the network loss calculation results.

Table 1 the network loss with same PV installation in head and different PV capacity

\begin{tabular}{|c|c|c|c|c|}
\hline $\begin{array}{c}\text { Total injection } \\
\text { power (MVA) }\end{array}$ & $\begin{array}{c}\text { DG active } \\
\text { power (MW) }\end{array}$ & $\begin{array}{c}\text { DG reactive } \\
\text { power (MVar) }\end{array}$ & Wattful loss & Reactive loss \\
\hline 10 & 0.5 & 0.101 & 0.733655 & 0.569794 \\
\hline 10 & 1.0 & 0.212 & 0.729269 & 0.566245 \\
\hline 10 & 1.5 & 0.315 & 0.606957 & 0.467451 \\
\hline 10 & 2.0 & 0.436 & 0.553069 & 0.423887 \\
\hline 10 & 2.5 & 0.568 & 0.505259 & 0.385207 \\
\hline 10 & 3.0 & 0.714 & 0.462399 & 0.350508 \\
\hline
\end{tabular}

Table 2 the network loss with same PV installation in middle and different PV capacity

\begin{tabular}{|c|c|c|c|c|}
\hline $\begin{array}{c}\text { Total injection } \\
\text { power (MVA) }\end{array}$ & $\begin{array}{c}\text { DG active } \\
\text { power (MW) }\end{array}$ & $\begin{array}{c}\text { DG reactive } \\
\text { power (MVar) }\end{array}$ & Wattful loss & Reactive loss \\
\hline 10 & 0.5 & 0.101 & 0.665467 & 0.515449 \\
\hline 10 & 1.0 & 0.212 & 0.553520 & 0.425485 \\
\hline 10 & 1.5 & 0.315 & 0.466963 & 0.355767 \\
\hline 10 & 2.0 & 0.436 & 0.403665 & 0.304588 \\
\hline 10 & 2.5 & 0.568 & 0.360473 & 0.269451 \\
\hline 10 & 3.0 & 0.714 & 0.335580 & 0.248892 \\
\hline
\end{tabular}

Table 3 the network loss with same PV installation in end and different PV capacity

\begin{tabular}{|c|c|c|c|c|}
\hline $\begin{array}{c}\text { Total injection } \\
\text { power (MVA) }\end{array}$ & $\begin{array}{c}\text { DG active } \\
\text { power (MW) }\end{array}$ & $\begin{array}{c}\text { DG reactive } \\
\text { power (MVar) }\end{array}$ & Wattful loss & Reactive loss \\
\hline 10 & 0.5 & 0.101 & 0.658144 & 0.509559 \\
\hline 10 & 1.0 & 0.212 & 0.557766 & 0.428724 \\
\hline 10 & 1.5 & 0.315 & 0.496022 & 0.378667 \\
\hline 10 & 2.0 & 0.436 & 0.465540 & 0.353493 \\
\hline 10 & 2.5 & 0.568 & 0.462671 & 0.350311 \\
\hline 10 & 3.0 & 0.714 & 0.483446 & 0.365958 \\
\hline
\end{tabular}

It can be seen that when the PV is connected to the node of network end point, the network loss is smaller, which shows that the reduction of network loss from the PV is greater. And, when the PV generation capacity is small than some capacity, the larger the PV power supply capacity, the smaller the distribution network loss. However, when the PV generation capacity exceeds some capacity, when the PV capacity continuatively grows, the distribution network loss get to increase.

\section{Analysis on the effects of the PV installation location to distribution network loss}

When the PV is connected to different node of a feed, and the PV capacity is consistent, the network loss is shown in table 4, table 5 and table 6 . 
Table 4 the network loss with same PV capacity and different PV installation (PV Active Power=1.0 MW PV Reactive Power=0.212 MVar)

\begin{tabular}{|c|c|c|}
\hline DGconnecting node & Wattful loss & Reactive loss \\
\hline 1 & 1.021568 & 0.810964 \\
\hline 2 & 0.913896 & 0.723423 \\
\hline 3 & 0.900327 & 0.712594 \\
\hline 4 & 0.855144 & 0.676656 \\
\hline 5 & 0.841594 & 0.665882 \\
\hline
\end{tabular}

Table 5 the network loss with same PV capacity and different PV installation (PV Active Power=1.8 MW PV Reactive Power=0.366 MVar)

\begin{tabular}{|c|c|c|}
\hline DGconnecting node & Wattful loss & Reactive loss \\
\hline 1 & 0.984891 & 0.781815 \\
\hline 2 & 0.807643 & 0.637608 \\
\hline 3 & 0.788585 & 0.622386 \\
\hline 4 & 0.729375 & 0.575289 \\
\hline 5 & 0.711330 & 0.560942 \\
\hline
\end{tabular}

Table 6 the network loss with same PV capacity and different PV installation (PV Active Power=2.7 MW PV Reactive Power=0.549 MVar)

\begin{tabular}{|c|c|c|}
\hline DGconnecting node & Wattful loss & Reactive loss \\
\hline 1 & 0.947472 & 0.752068 \\
\hline 2 & 0.707510 & 0.556670 \\
\hline 3 & 0.687186 & 0.540407 \\
\hline 4 & 0.630579 & 0.495365 \\
\hline 5 & 0.612329 & 0.480854 \\
\hline
\end{tabular}

It shows that when the PV is connected to the node is the same feed, if the node is closer to the end point, then the network loss reduce more sensibly.

\section{Conclusion}

With the PV generation connected, the photovoltaic power installation location and the generating capacity both affect the distribution network loss.

1) When the PV is connected to the node of network end point, the network loss reduce more sensibly.

2) When the PV generation capacity is small than some capacity, the larger thePV power supply capacity, the smaller the distribution network loss.

3) When the PV generation capacity exceeds some capacity, when the PV capacity continuatively grows, the distribution network loss get to increase.

\section{References}

[1]. ZOU Bi-chang, LI tao, TANG Tao-bo, Impacts of Distributed Generation on Power Distribution System, SHANXI ELECTRIC POWER, 2011, 39(5). 
[2]. LIU Lei, JIANG Hui, PENG Jian-chun, Impact of Distributed Generation on Distribution System Power Loss and Voltage Profile, COMPUTER SIMULATION, 2010, 27(4).

[3]. KOU Feng-hai, Impacts of Distributed Photovoltaic Power Sources on Distribution Network Loss, Advances of Power System \& Hydroelectric Engineering, 2011, 27(11).

[4]. YU Wei-guo, XING You-jing, ZHOU Xin-feng, ZHAO Guo-liang, CHENG Ning, Analysis on Technical Line Losses of Power Grids and Countermeasures to Reduce Line Losses, POWER SYSTEM TECHNOLOGY, 2006, 30(18).

[5]. YU Xu-yang, Theoretical line loss calculation method of middle-low voltage distribution network, HUNAN ELECTRIC POWER, 2008, 28(1).

[6]. TAN Mu-zi, LI Xiao-song, Calculation of Theoretical Line Loss for Rural Low-Voltage Distribution Networks under Unbalanced Three-Phase Loads based on Time Segment, Journal of Hunan Institute of Science and Technology (Natural Sciences), 2015, (1). 